\title{
Coulomb per Cubic Meter
}

National Cancer Institute

\section{Source}

National Cancer Institute. Coulomb per Cubic Meter. NCI Thesaurus. Code C68910.

A unit of volumetric electrical charge density designated as the charge equal to one coulomb distributed over the volume equal to one cubic meter. 